Article

\title{
Effect of Hexagonal Phase Content on Wear Behaviour of AlTiN Arc PVD Coatings
}

\author{
Joern Kohlscheen * and Christian Bareiss \\ Kennametal GmbH, Altweiherstrasse 27-31, 91320 Ebermannstadt, Germany; christian.bareiss@kennametal.com \\ * Correspondence: joern.kohlscheen@kennametal.com; Tel.: +49-919-472-0152
}

Received: 30 January 2018; Accepted: 9 February 2018; Published: 13 February 2018

\begin{abstract}
In this study, the effect of increasing aluminum content and magnetic steering field strength on the structure and wear behavior of arc PVD AlTiN coatings is discussed. Deposition was done by means of an industrial-scale PVD unit for tool coating. The aluminium content in the AlTi source material was increased from 67 to 73 at.\%. We applied two settings of the magnetic field that steers the arc across the cathode surface thereby evaporating the AlTi alloy differently. The resulting coating thickness ranged from 3.5 to about $7 \mu \mathrm{m}$. Cemented tungsten carbide was used as substrate material. Coating properties like hardness, adhesion, and crystal phases were analyzed by indentation and X-ray diffraction, respectively. The wear behaviour of the different AlTiN hard coatings were investigated in two ways. In a first idealized test, cyclic impacting was done applying a constant force. The resulting wear pattern was quantified by an Alicona multi-focus microscope. A second wear test was done by metal cutting under realistic conditions. Fly milling of ductile cast iron (EN-GJS-700) was performed with regular interruptions in order to measure the increasing wear mark. As expected, aluminium contents above 67 at.\% (in the metal fraction of the coating) lead to a decreased wear resistance as the soft hexagonal phase exceeds values of a few vol.\%. However, it was found that the formation of the hexagonal phase can be effectively influenced and delayed by increasing the magnetic steering field at the cathode. The wear behavior observed in cyclic impact testing corresponds well to results obtained with the more complex loading situation encountered in milling.
\end{abstract}

Keywords: PVD; AlTiN; coating; cutting tool; wear resistance; milling

\section{Introduction}

PVD TiAlN thin films are widely used as protective coatings in the cutting tool industry. PVD processes like magnetron sputtering or cathodic arc deposition benefit from the fact that metastable phases can be obtained due to rapid cooling ("quenching") of the deposited material. This makes it possible to solve higher amounts of foreign atoms into a desired crystal lattice than would be possible in thermodynamic equilibrium. In the case of AlTiN, Al atoms are substituting Ti atoms on their lattice sites in the face centered cubic TiN crystal. The effect of variation in $\mathrm{Al}$ content (fraction of $x$ in $\mathrm{Ti}_{1-x} \mathrm{Al}_{x} \mathrm{~N}$ ) has been the topic of many studies, and a seminal review was published by PalDey and Deevi [1]. It is generally accepted that increasing the aluminium content from $x=0.5$ to about 0.65 (Al:Ti ratio of about 2:1) will improve the tool performance in many applications [2-4]. The main reasons are that hardness and compressive stress are further increased by distortion of the cubic crystal lattice. Also, enrichment with $\mathrm{Al}$ will improve the ability to form protective oxide layers in the cutting zone during a machining operation. When trying to add even more $\mathrm{Al}$, the softer hexagonal AlN (wurtzite) phase will finally prevail. The same effect can be obtained by annealing, which leads to segregation of metastable AlTiN into the thermodynamically stable AlN and TiN through an intermediate stage of cubic AlN precipitates [5,6]. Common PVD processes used in tool 
coating offer some possibilities for shifting the onset of hexagonal phase formation by adjusting process parameters. Andersson et al. found that a reduced magnetic field strength near the arc PVD cathode stabilizes the cubic phase $[7,8]$. Increasing the substrate bias voltage, alloying elements, and nano-layering (superlattices) can also have stabilising effects [3,9-11]. On the other hand, it has been observed that adding some softer hexagonal phase can be used to tailor hardness and toughness of $\mathrm{Al}$ rich AlTiN coatings for a specific application [12-14]. Some studies emphasize the importance of microstructure in mono and dual phase Ti-Al-N coatings to their response to mechanical load [15,16]. To understand the effect of any compositional difference on wear resistance, cyclic impact testing has been shown to be a valuable tool [17-21]. In this work, we will focus on the wear behavior of AlTiN arc PVD coatings with borderline $\mathrm{Al}$ contents and different shares of cubic and hexagonal phase.

\section{Materials and Methods}

\subsection{Coating Deposition}

The depositions were carried out in state-of-the art industrial PVD equipment with six circular evaporators. Each evaporator uses both a permanent magnet and an adjustable electromagnetic coil to steer the arc. The confinement rings that are placed above the cathode material have a patented design to stabilise the cubic phase at higher magnetic fields [14]. The magnetic field strength was determined to be $100 \mathrm{~A} / \mathrm{cm}$ at the cathode material surface (center) without applied current. The coil current was set to be either zero ("mag off") or close to $1 \mathrm{~A}$ ("mag on"). The coatings were deposited in a pure nitrogen atmosphere at a pressure of 3.5 Pa and a cathode current of $200 \mathrm{~A}$. The substrate bias voltage was set to $-60 \mathrm{~V}$. Temperature in the chamber during deposition was kept constant at about $500{ }^{\circ} \mathrm{C}$ controlled by thermocouples near the heating elements. Powder metallurgical AlTi cathodes with a diameter of $120 \mathrm{~mm}$ were used. The deposition time was kept constant at $150 \mathrm{~min}$. Square- and rhombic-shaped samples of cemented carbide with $6 \mathrm{wt} . \%$ cobalt binder were used (SNMA432 and CNMG432). The samples were washed and dry-blasted with alumina powder to condition surfaces for coating.

\subsection{Coating Analysis and Testing}

Coating adhesion was determined by a Rockwell hardness tester with a $120^{\circ}$ conical diamond tip indenter and a load of $100 \mathrm{~kg}$. The indentation marks were photographed with a microscope at $20 \times$ magnification. Hardness and reduced elastic modulus were determined using a Fischerscope instrumented hardness tester (Fischer, Sindelfingen, Germany) with a load of $100 \mathrm{mN}$. Crystal phase determination of the resulting AlTiN films was determined by a Panalytical X-pert diffractometer using Bragg Brentano geometry. The software of this instrument allows to calculate the shares of crystal phases that are detected (here: cubic face-centered and hexagonal close-packed phase).

Coating resistance against abrasive and fatigue wear was determined by a custom made cyclic impact tester. The principle is described in [20]. Figure 1a shows the setup with a test specimen and a spherical-shaped indenter. The specialty of this instrument is that the sample is mounted on an inclined lever. Thereby, the impact occurs not only at the initial point of contact, but is followed by sliding of about $5 \mathrm{~mm}$ on the sample surface until the indenter is stopped by the counteracting lever force $(100 \mathrm{~N})$. The amount of wear after 3000 impacts was quantified by an Alicona 3D imaging system (Alicona, Graz, Austria), which makes it possible to calculate volumes of worn material.

A fly milling test with the tool shown in Figure $1 \mathrm{~b}$ was performed which represents realistic wear conditions in machining. Table 1 summarises the parameters set for the test. Ductile cast iron material EN-GJS-700 (TRS = 700 MPa) was machined without coolant until reaching $1.8 \mathrm{~m}$ of cutting length. The test was interrupted regularly in order to measure the growing wear mark at the cutting edge by means of a microscope at $50 \times$ magnification. The total wear at test end was also measured with the Alicona device. 


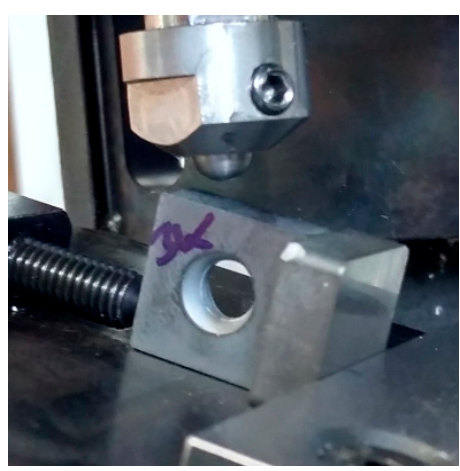

(a)

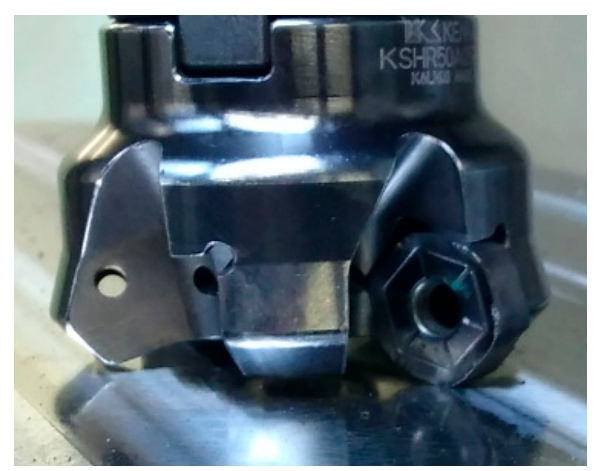

(b)

Figure 1. Wear test equipment, cyclic impact tester (a) and face milling test with a single insert (b).

Table 1. Wear conditions in machining.

\begin{tabular}{cc}
\hline Machining Parameter & Value \\
\hline Cutting speed $[\mathrm{m} / \mathrm{min}]$ & 300 \\
Feed rate [mm/rev] & 0.2 \\
Radial engagement [mm] & 37.5 \\
Depth of cut [mm] & 2 \\
Total cutting length [mm] & 1800 \\
Workpiece material & EN-GJS-700 \\
\hline
\end{tabular}

\section{Results and Discussion}

\subsection{Coating Analysis}

Table 2 contains an overview of the $\mathrm{Al}_{x} \mathrm{Ti}_{1-x} \mathrm{~N}$ coatings deposited along with some structural and mechanical properties that were measured. Three cathode compositions with the Al:Ti ratio shown were chosen to deposit coatings at and beyond the critical ratio of 67:33 (or 2:1). By doing this, the transitional zone where the hexagonal phase starts to form can be sampled. EDX measurements of the film's aluminium concentration showed 1-2 at.\% lower values in all cases due to some preferential re-sputtering of $\mathrm{Al}$ in the growing film.

The other variable that was changed in this investigation was the coil current of the electromagnet at the cathode, which was set to either zero (leaving only a permanent field) or to a non-zero value, adding to magnetic field strength. Table 2 already shows that with increasing aluminium content from 67 to 73 at. $\%$, the share of the hexagonal phase rises quickly to $30-50$ vol.\%. The error in this evaluation is estimated to be about $5 \mathrm{vol} . \%$, so values were rounded. It can be seen that if a coil current is applied, it helps to stabilize the cubic phase, and the amount of the hexagonal phase could be reduced by up to $20 \mathrm{vol} . \%$. The current increases the intensity of the magnetic field near the cathode surface and hence the amount of ionized gas particles (forming the plasma). This would normally drive the growing film toward equilibrium by increased adatom mobility, as proposed by Andersson et al. for standard cathode rings [7]. In this case, however, the patented cathode ring helps to confine the plasma and charged particles near the cathodes, as explained in [22]. It is known that a higher magnetic field leads to faster arc movement on the cathode surface and results in less evaporation and deposition rate [23], just as observed here. As reduced deposition rate means fewer particles per time interval and thus less energy input, the adatom mobility could actually be reduced and favour the metastable cubic phase in AlTiN, in contrast to what is observed with conventional cathode arrangements allowing uncontrolled outward streaming of charged particles. As a weakened magnetic field means that the arcs dwell longer at a given spot, we can expect more so-called droplets being evaporated along with the metal vapor. Figure 2 confirms the increased presence of droplets in weak magnetic field configuration (Figure $2 b$ ) when compared to increased magnetic field strength (Figure 2a). 
Table 2. Overview of AlTiN variants deposited and selected coating properties.

\begin{tabular}{|c|c|c|c|c|}
\hline Cathode Material & Coil Magnet on & Coating Thickness $[\mu \mathrm{m}]$ & $H / E_{\mathrm{r}}$ & Hex. Phase [vol.\%] ${ }^{1}$ \\
\hline Al67Ti33N & Yes & 3.4 & $32 / 450(0.07)$ & 0 \\
\hline Al67Ti33N & No & 5.8 & $23 / 280(0.08)$ & 20 \\
\hline Al70Ti30N & Yes & 4.4 & $24 / 320(0.08)$ & 20 \\
\hline Al70Ti30N & No & 5.7 & $23 / 280(0.08)$ & 30 \\
\hline Al73Ti27N & Yes & 4.5 & $23 / 320(0.07)$ & 30 \\
\hline Al73Ti27N & No & 6.7 & $20 / 270(0.07)$ & 50 \\
\hline
\end{tabular}

${ }^{1}$ rounded values, see text.

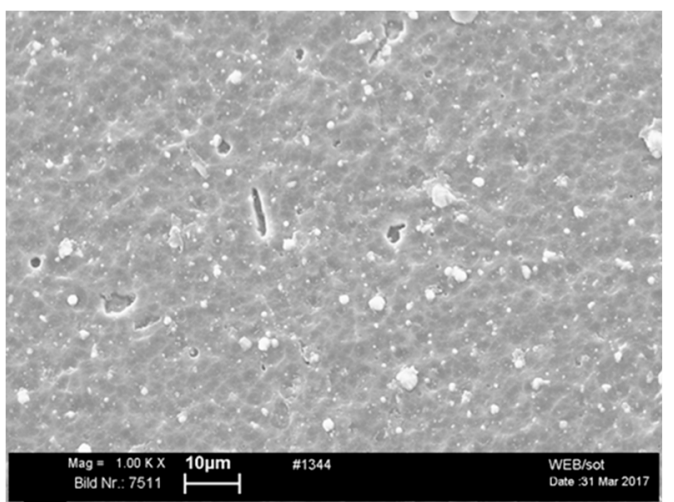

(a)

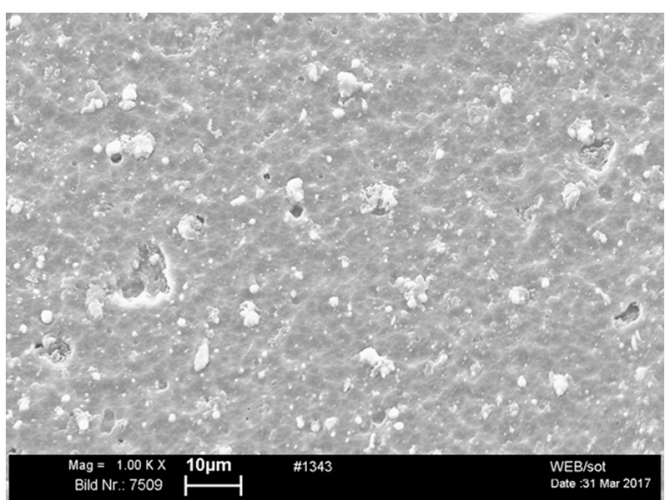

(b)

Figure 2. Comparison of two Al0.73Ti0.33N coatings obtained with magnetic coil current at the cathode (a) turned on ("mag on") and (b) turned off ("mag off").

Mechanical properties obtained by nano-indentation are also listed in Table 2. With higher Al content of the coatings, the measured hardness values decrease significantly from 32 GPa to about $22 \mathrm{GPa}$ for all variants which is explained by the presence of the softer hexagonal phase. Similar values were reported by Chen et al. $[5,10]$. It should be pointed out that some stabilisation occurs on the lower level. It is interesting to note that the $H / E_{\mathrm{r}}$ ratio stays almost constant near 0.07 and deviates somewhat from results presented by Hörling et al. [4] but agrees well with Chen et al. using similar coating equipment [10].

In order to better visualise coating adherence and toughness, a static indentation with a diamond tip was performed. The resulting circular-shaped indents are contained in Figure 3. Coatings deposited with increasing $\mathrm{Al}$ content and magnetic steering field are shown in Figure 3a, whereas coatings with the coil current (magnetic field) off are presented in Figure 3b. As can be seen, all coatings adhere well without large-scale delamination (i.e., passing the $100 \mathrm{~kg}$ load test). The other obvious finding is that crack lengths are generally reduced for coatings in the lower row and to some extent in the upper right image (Al73Ti33N with mag on). Instead, fine cracks and some flaking near the indent rim are visible.

Comparing with Table 2, one can conclude that around 30 vol. $\%$ of the hexagonal phase the coatings becomes tough enough to avoid heavy cracking. It must be mentioned that coatings of the lower row had higher thickness. However, indentation on the coating with a thickness close to $3 \mu \mathrm{m}$ (mag off) resulted in a very similar pattern (no long cracks). The somewhat reduced adhesion at the indent rim is likely due to reduced cohesion between the two distinct phases, as proposed by Henry et al. [15]. 


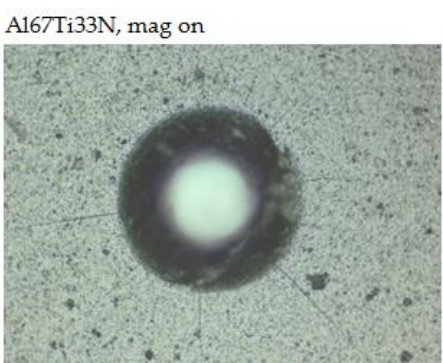

A170Ti30N, mag on

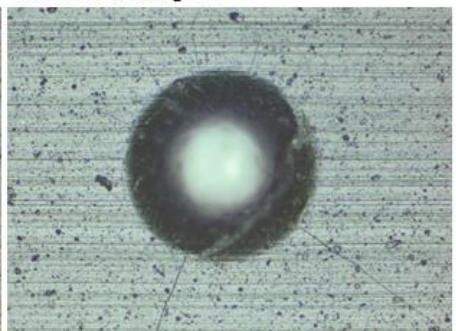

(a)

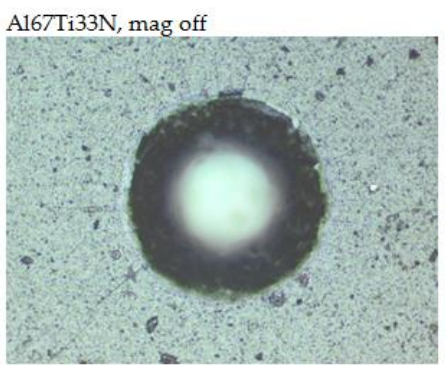

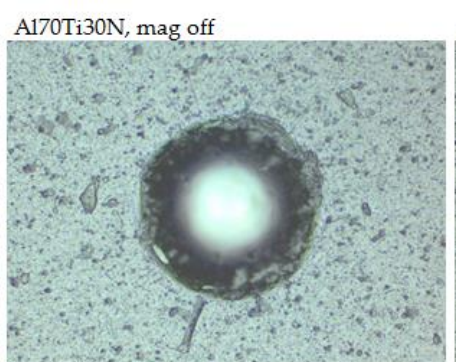

(b)
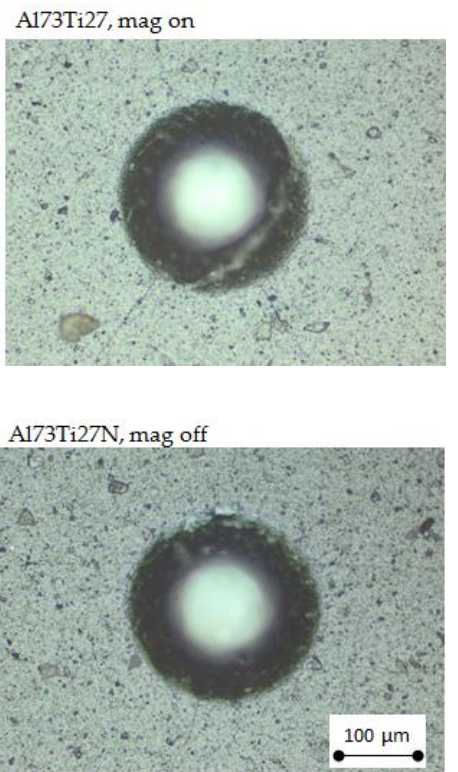

Figure 3. Indentation images of all AlTiN variants: (a) $x=0.67,0.7,0.73$ with coil current on ("mag on");

(b) the same sequence with coil current set to zero ("mag off").

As the coatings are deposited with oversaturation of $\mathrm{Al}$ in the TiN lattice, small grain sizes are expected. Figure 4 shows a typical XRD diagram and a cross-sectional structure of a coating with an $\mathrm{Al}$ content of 70 at.\%. The micro-structure appears almost without features and only some slight indication of vertical grain growth. The diffraction diagram revealed the expected peaks of the cubic phase (fcc or "c-AlTiN"), namely 111 and 200. The latter peak shows a higher intensity corresponding to vertically oriented grains. This is in good agreement with previous findings [4,13]. With an increasing amount of $\mathrm{Al}$ in the coating, all diffraction peaks become broader due to grain size reduction, and coating features vanish in imaging. The 10-10, 10-11 and 11-20 reflexes of the hexagonal phase ("h-AlTiN") could be detected for all variants except A167Ti33N with coil current on [7]. The substrate peaks are also visible (“WC").

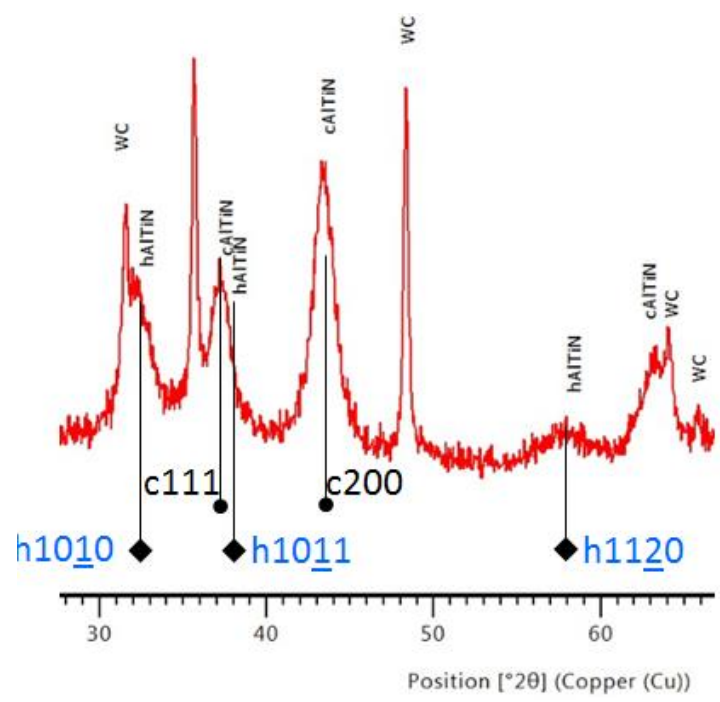

(a)

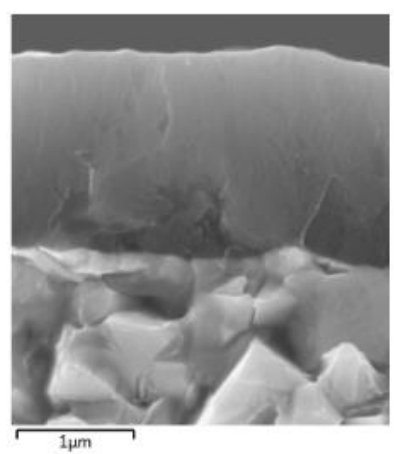

(b)

Figure 4. XRD scan of coating Al0.7Ti0.3N deposited with mag on (a) and related SEM cross-section (b). 


\subsection{Wear Test by Cyclic Impacting}

The observed differences in hardness and modulus should have some distinct consequences in dynamical response of the various coatings. A cyclic impact test was used to determine differences in wear and fatigue behaviour. The evaluation of worn volume below the reference plane (sample surface) after 3000 impacts is shown in Figure 5a. Not surprisingly, with decreasing hardness, the coatings become more vulnerable to abrasive wear. The variants Al67Ti33N and Al70Ti30N showed the lowest wear values. Interestingly, if the soft hexagonal phase is present in substantial amounts (mag off), the wear mainly occurs in the sliding zone, whereas for harder coatings (mag on), the zone of first impact is affected more. As an example, Figure $5 b$ shows the comparison of wear tracks at test end, obtained with Al70Ti30N/coil current on (upper image) and coil current off (lower image). In the lower image, exposed substrate is visible due to the coating having flaked off. The coating in the image above remains intact. As already found in static indentation testing (Figure 3), low coil currents lead to somewhat less adherent coatings, which tend to reduce resistance against shear forces occurring in sliding. On the other hand, the wear track and the oval zone of first impact is narrower and less pronounced for the softer coating, which yields earlier under loading.

Although the coatings deposited with "mag off" are thicker than the ones deposited with "mag on", the wear pattern did not change significantly when testing a thinner coating variant with a thickness around $4 \mu \mathrm{m}$ (not shown here).

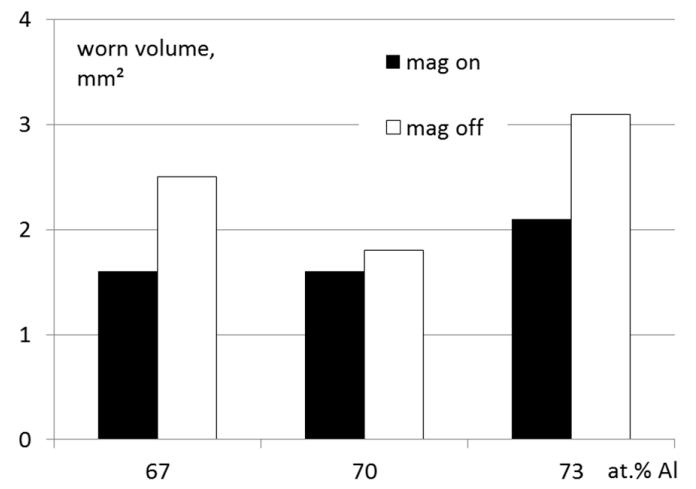

(a)

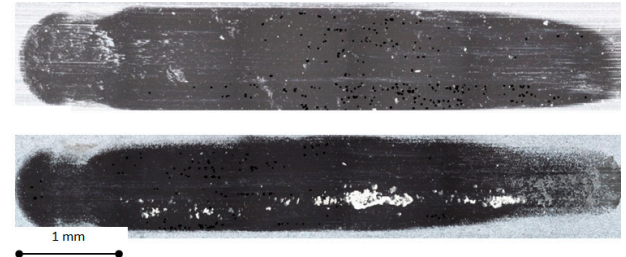

(b)

Figure 5. Wear volume after 3000 impacts (a) and exemplary wear marks of coating Al70Ti30N with mag on (upper image)/mag off (lower image) (b).

\subsection{Wear Test by Fly Milling}

There is a need in hard coating development to judge the wear resistance of a tool in a cutting operation from a simplified wear test like the one described here. To put this approach to the test, milling inserts coated in the same batch as the impact test samples were used in a face milling operation (fly cutting, no coolant), and the resulting flank wear mark was measured. Cast iron was chosen as work-piece material. It is known that this material leads mainly to abrasive cutting edge wear (whereas steel would add an adhesive wear component). In addition, fly cutting also represents a cyclic loading of the tool which resembles impact testing. Figure 6a shows the evolution of the flank wear mark obtained for inserts coated with the six AlTiN variants. The width of the flank wear mark perpendicular to the cutting edge was determined by periodically. The milling test was stopped after cutting for $1.8 \mathrm{~m}$, which equals about 9000 loading cycles of the insert. It can be seen that AlTiN coatings deposited with the mag off setting led to more wear (open marks). For the coatings with magnetic coils turned on (mag on), the Al70TiN showed a slightly better tool performance than Al67TiN (filled marks). In general, the wear in milling follows a similar trend as observed in impact testing.

Figure $6 \mathrm{~b}$ compares images of the rake face at test end. In general, without assisting magnetic field (mag off), there is an increased amount of crater wear and a tendency for coating failure where 
the highest loads occur: at the depth of cut (i.e., $2 \mathrm{~mm}$, wear mark to the right, black arrow) and the secondary cutting edge (white arrow). The coating variants deposited with coils on (mag on) all had much less wear at these spots due to higher hardness and improved adhesion. The trends correspond well to the indent images of Figure 3.

As mentioned, the usual way to evaluate wear resistance of cutting edges is to measure the resulting width of the wear mark at the tool flank below the main cutting edge. Less often, crater wear on the rake face is considered. Cratering occurs in a zone where the chip is in actual contact with the tool during the cutting and shear off process. Looking at Figure 5, it is obvious that flank wear data are too close to discriminate sufficiently between the coating variants and do not provide the full picture. Therefore, we also determined the wear volume at the central section where highest flank wear occurs (see Figure 6b, center section with a width of $500 \mu \mathrm{m}$ ). To do this, scanning of the new and worn edges was performed.

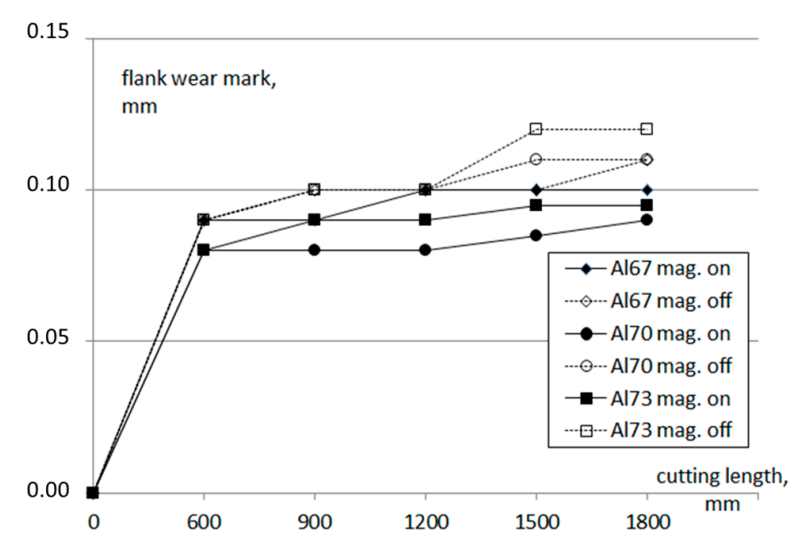

(a)

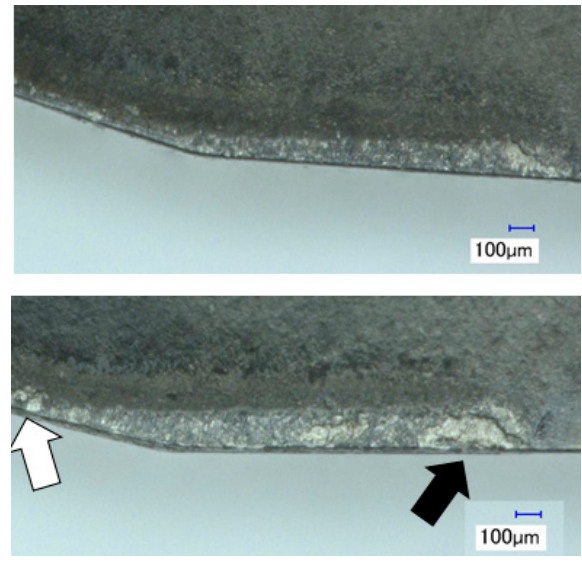

(b)

Figure 6. Evolution of flank wear (a) and images of rake face at test end (b) for coating Al70Ti30N with mag on (upper image) and mag off (lower image).

Figure 7a shows the resulting profile after the worn contour has been subtracted from the new one. This measurement takes into account the wear extending onto the rake face and contains more information than a simple width measurement of the flank wear mark. Figure $7 \mathrm{~b}$ shows the results of the calculated wear volume at the specified cutting zone after $1.8 \mathrm{~m}$ of cutting distance.

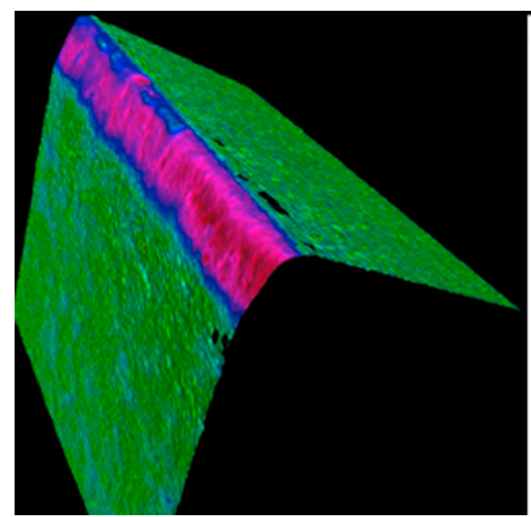

(a)

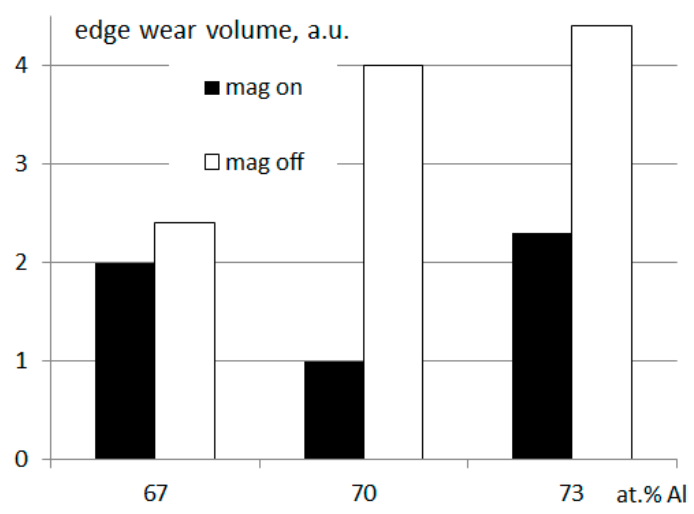

(b)

Figure 7. False color differential image of a worn cutting edge section (500 $\mu \mathrm{m}$ wide) (a) and calculated wear volumes (b). 
The good performance of the Al70Ti30N coating (deposited with coil current on) in both tests could be explained by the presence of about $20 \mathrm{vol} . \%$ hexagonal phase while still retaining a higher modulus $\left(E_{\mathrm{r}}>300 \mathrm{GPa}\right)$. This configuration seems to be beneficial for wear resistance despite lower hardness, as some added toughness is counteracting fatigue wear (crack formation and growth). However, the window seems quite narrow, and other detrimental effects like deteriorating adhesion soon begin to undermine the ability to protect the substrate.

In summary, the results of both wear tests show very good agreement, as is demonstrated by Table 3. It ranks the amounts of wear volume determined after impact testing and milling. Except for two cases, the cutting materials behave very similarly.

Table 3. Ranking of AlTiN variants according to their performance in impacting and milling.

\begin{tabular}{ccccc}
\hline Cathode Material & Coil Magnet on & Rank Impact Wear & Rank Tool Wear & Agreement \\
\hline Al67Ti33N & Yes & 2 & 2 & Yes \\
Al67Ti33N & No & 4 & 3 & - \\
Al70Ti30N & Yes & 1 & 1 & Yes \\
Al70Ti30N & No & 5 & 5 & Yes \\
Al73Ti27N & Yes & 3 & 4 & - \\
Al73Ti27N & No & 6 & 6 & Yes \\
\hline
\end{tabular}

\section{Conclusions}

AlTiN coatings were deposited by arc PVD on carbide samples with variation of Al content and cathode magnetic field strength. Six coating variants were analyzed and subject to impact and milling tests. Amounts of more than 67 at.\% of Al lead to a softening of the coating due to formation of the hexagonal wurtzite phase. This trend can be delayed by increasing the magnetic field at the cathode. We found that a reduced hardness does not mean an immediate decrease in wear resistance. A certain share of soft phase can help to improve crack resistance. This is especially useful under cyclic loading conditions involving fatigue wear, as in milling and impacting, as described. Evaluation of scatter in impact testing and comparison to other work piece materials is currently in preparation to extend the predictive ability of this testing method.

Author Contributions: Joern Kohlscheen wrote this paper, supervised planning, and coordinated the experiments. Christian Bareiss performed coating deposition and impact testing.

Conflicts of Interest: The authors declare no conflict of interest.

\section{References}

1. PalDey, S.; Deevi, S.C. Single layer and multilayer wear resistant coatings of (Ti,Al)N: A review. Mater. Sci. Eng. A 2003, 342, 58-79. [CrossRef]

2. Inspektor, A.; Salvador, P.A. Architecture of PVD coatings for metalcutting applications: A review. Surf. Coat. Technol. 2014, 257, 138-153. [CrossRef]

3. Kumar, V.; Penich, R. Stabilization of cubic phase in AlTiN coatings using anode configurations. Int. J. Refract. Met. Hard Mater. 2016, 60, 113-117. [CrossRef]

4. Hörling, A.; Hultman, L.; Oden, M.; Sjölen, J.; Karlsson, L. Mechanical properties and machining performance of $\mathrm{Ti}_{1-x} \mathrm{Al}_{x} \mathrm{~N}$ coated cutting tools. Surf. Coat. Technol. 2005, 191, 384-392. [CrossRef]

5. Chen, L.; Paulitsch, J.; Du, Y.; Mayrhofer, P.H. Thermal stability and oxidation resistance of Ti-Al-N coatings. Surf. Coat Technol. 2012, 206, 2954-2960. [CrossRef] [PubMed]

6. Grossmann, B.; Schalk, N.; Czettl, C.; Pohler, M.; Mitterer, C. Phase composition and thermal stability of arc evaporated $\mathrm{Ti}_{1-x} \mathrm{Al}_{x} \mathrm{~N}$ hard coatings with $0.4 \leq x \leq 0.67$. Surf. Coat. Technol. 2017, 309, 687-693. [CrossRef]

7. Andersson, J.M.; Vetter, J.; Müller, J.; Sjölen, J. Structural effects of energy input during growth of $\operatorname{Ti}_{1-x} \mathrm{Al}_{x} \mathrm{~N}$ coatings by cathodic arc evaporation. Surf Coat. Technol. 2014, 240, 211-220. [CrossRef]

8. Sjölen, J.; Andersson, J.; Vetter, J.; Müller, J. PVD Coating for Metal Machining. European Patent EP 2,835,445 A1, 11 February 2015. 
9. Schlögl, M.; Paulitsch, J.; Mayrhofer, P.H. Thermal stability of CrN/AlN superlattice coatings. Surf. Coat. Technol. 2014, 240, 250-254. [CrossRef]

10. Chen, L.; Xu, Y.X.; Du, Y.; Liu, Y. Effect of bilayer period on structure, mechanical and thermal properties of TiAlN/AlTiN multilayer coatings. Thin Solid Films 2015, 592, 207-214. [CrossRef]

11. Rafaja, D.; Poklad, A.; Klemm, V.; Schreiber, G.; Heger, D.; Sima, M. Microstructure and hardness of nanocrystalline $\mathrm{Ti}_{(1-x-y)} \mathrm{Al}_{x} \mathrm{Si}_{y} \mathrm{~N}$ thin films. Mater. Sci. Eng. A 2007, 462, 279-282. [CrossRef]

12. Ni, W.; Penich, R.M.; Liu, Y.; Beblo, M.F. Aluminum Titanium Nitride Coating and Method of Making the Same. U.S. Patent 8,277,958 B2, 8 August 2012.

13. Kutschej, K.; Mayrhofer, P.H.; Kathrein, M.; Polcik, P.; Tessadri, R.; Mitterer, C. Structure, mechanical and tribological properties of sputtered $\mathrm{Ti}_{1-x} \mathrm{Al}_{x} \mathrm{~N}$ coatings with $0.5 \leq x \leq 0.75$. Surf. Coat. Technol. 2005, 200, 2358-2365. [CrossRef]

14. Kumar, V.; Penich, R.M.; Leicht, P.; Liu, Y. Low Stress Hard Coatings and Applications Thereof. U.S. Patent 9,168,664 B2, 19 February 2015.

15. Henry, P.; Pac, M.J.; Rousselot, C.; Tuilier, M.H. Wear mechanisms of titanium and aluminium nitride coatings: A microtribological approach. Surf. Coat. Technol. 2013, 223, 79-86. [CrossRef]

16. Pemmasani, S.P.; Valleti, K.; Gundakaram, R.C.; Rajulapati, K.V.; Mantripragada, R.; Koppoju, S.; Joshi, S.V. Effect of microstructure and phase constitution on mechanical properties of $\mathrm{Ti}_{1-x} \mathrm{Al}_{x} \mathrm{~N}$ coatings. Appl. Surf. Sci. 2014, 313, 936-946. [CrossRef]

17. Bouzakis, K.D.; Mirisidis, I.; Michailidis, N.; Lili, E.; Sampris, A.; Erkens, G.; Cremer, R. Wear of tools coated with various PVD films: Correlation with impact test results by means of FEM simulations. Plasma Process Polym. 2007, 4, 301-310. [CrossRef]

18. Bouzakis, K.D.; Michailidis, N.; Bouzakis, E.; Katirtzoglou, G.; Makrimallakis, S.; Gerardis, S.; Pappa, M.; Klocke, F.; Schalaster, R.; Gorgels, C. Cutting performance of coated tools with various adhesion strength quantified by inclined impact tests. CIRP Ann. Manuf. Technol. 2011, 60, 105-108. [CrossRef]

19. Skordaris, G.; Bouzakis, K.D.; Charalampous, P.; Bouzakis, E.; Paraskevopoulou, R.; Lemmer, O.; Bolz, S. Brittleness and fatigue effect of mono- and multi-layer PVD films on the cutting performance of coated cemented carbide inserts. CIRP Ann. Manuf. Technol. 2014, 63, 93-96. [CrossRef]

20. Chen, Y.; Nie, X. Study on fatigue and wear behaviors of a TiN coating using an inclined impact-sliding test. Surf. Coat. Technol. 2011, 206, 1977-1982. [CrossRef]

21. Mo, J.L.; Zhu, M.H.; Leyland, A.; Matthews, A. Impact wear and abrasion resistance of CrN, $\mathrm{AlCrN}$ and AlTiN PVD coatings. Surf. Coat. Technol. 2013, 215, 170-177. [CrossRef]

22. Krassnitzer, H.; Hagmann, J. Arc Deposition Source Having a Defined Electric Field. World Patent Application WO 2011,160,766 A1, 29 December 2011.

23. Lang, W.C.; Xiao, J.Q.; Gong, J.; Sun, C.; Huang, R.F.; Wen, L.S. Study on cathode spot motion and macroparticles reduction in axisymmetric magnetic field-enhanced vacuum arc deposition. Vacuum 2010, 84, 1111-1117. [CrossRef]

(C) 2018 by the authors. Licensee MDPI, Basel, Switzerland. This article is an open access article distributed under the terms and conditions of the Creative Commons Attribution (CC BY) license (http:// creativecommons.org/licenses/by/4.0/). 